\title{
Miradas sobre el Chaco: una aproximación a la intervención del Instituto Geográfico Argentino en la apropiación material y simbólica de los territorios chaqueños (1879-1911)
}

\author{
Carla Lois \\ Universidad de Buenos Aires \\ carlaml@ciudad.com.ar
}

Fecha de recepción: 2 de septiembre de 2002

Fecha de aceptación: 1 de octubre de 2002

\section{Resumen}

En este trabajo se analiza el rol del Instituto Geográfico Argentino (IGA), fundado en 1879, en la producción, circulación, resignificación, mitificación y abandono de imágenes territoriales respecto del Chaco; una región calificada como desértica y habitada por una serie de grupos indígenas, cuyo sometimiento solo se logró tras una serie de campañas militares adelantadas entre 1886 y 1911. Dichas imágenes, inscritas en discursos y prácticas institucionales, tuvieron un lugar significativo en las formas de pensar y de operar sobre el territorio nacional en el contexto del proceso de consolidación y definición territorial que se dio a finales del siglo XIX y comienzos del XX. Estos discursos y prácticas institucionales cobrarían particular importancia si se considera que la mayoría de los miembros del IGA eran funcionarios del gobierno y militares que participaron activamente en las campañas destinadas a consolidar la apropiación material de los territorios indígenas, contribuyendo así a planificar científicamente el diseño del territorio nacional a la medida de las necesidades políticas de la época.

Palabras clave: EL CHACO, INSTITUTO GEOGRÁFICO ARGENTINO, TERRITORIO, NACIÓN, CARTOGRAFÍA, ARGENTINA, SIGLO XIX, SIGLO XX.

\begin{abstract}
This text analyzes the role of the Instituto Geográfico Argentino (IGA), founded in 1879, in the production, circulation, re-signification, mythification and abandonment of territorial images related to the Chaco, a region considered to be a desert and inhabited by several indigenous groups whose submission was only achieved after several military campaigns between 1886 and 1911. These images, inscribed in institutional practices and discourse, held a significant place in the way of thinking about and operating over the national territory during the processes of territorial consolidation and definition that took place at the end of the $19^{\text {th }}$ and beginning of the $20^{\text {th }}$ centuries. These institutional practices and discourses take on greater importance if one considers that the majority of the members of the IGA were government and military officials that actively participated in those campaigns destined to consolidate the material appropriation of the indigenous territories, contributing in this way to the scientific planning of the national territory according to the political necessities of the time.
\end{abstract}

Key words: EL CHACO, INSTITUTO GEOGRÁFICO ARGENTINO, TERRITORY, NATION, CARTOGRAPHY, ARGENTINA, $19^{\mathrm{TH}}$ CENTURY, $20{ }^{\mathrm{TH}}$ CENTURY.

Fronteras de la Historia 7 (2002)

(C) ICANH 


\section{Introducción}

Diferentes estudios históricos ${ }^{1}$ reconocen al período comprendido entre los años 1853 y 1880 como de formación del Estado nación argentino. Ese proceso de formación y consolidación del Estado requirió de un proceso de definición del territorio estatal, es decir, del ámbito geográfico donde las instituciones estatales ejercerían sus capacidades de control material y simbólico.

La definición territorial implicó la delimitación de las fronteras exteriores y la organización de vastos territorios existentes fuera de los límites o posesión de las provincias ${ }^{2}$. Esos territorios, que ocupaban poco menos que la mitad del territorio estatal, eran conocidos como el Chaco (en la sección noreste del territorio estatal) y la Patagonia (al sur), y tenían la particularidad de conformar dominios indígenas

A diferencia del rápido y "exitoso" exterminio indígena de la Patagonia (1879), en el Chaco se llevaron a cabo sucesivas campañas militares entre 1884 y 1911 hasta que las fuerzas oficiales lograron reducir a los indios y avanzar militarmente hasta la actual frontera estatal ${ }^{3}$. En ese contexto, se multiplicaron prácticas y discursos científicos que apoyaron la empresa militar y los intereses políticos orientados a definir y a consolidar un territorio exclusivo y excluyente para el Estado nación argentino. Curiosamente, la conquista de los desiertos del Chaco y la Patagonia coincidió temporalmente con la fundación de dos instituciones geográficas: en 1879, el Instituto Geográfico Argentino (en adelante, también IGA) y, en 1881, la Sociedad Geográfica Argentina. En este trabajo proponemos analizar el rol del IGA en la producción, circulación, resignificación, mitificación y abandono de imágenes territoriales respecto del Chaco que, inscritas en discursos y prácticas institucionales, tuvieron un lugar significativo en las formas de pensar y de operar sobre el territorio nacional en el contexto del proceso de consolidación y definición territorial. Estos discursos y prácticas institucionales cobrarían particular importancia si se considera que la mayoría de los miembros del IGA eran funcionarios del gobierno y militares que participaron activamente en las campañas destinadas a consolidar la apropiación material de los territorios indígenas, contribuyendo así a planificar científicamente el diseño del territorio nacional a la medida de las necesidades políticas de la época.

\footnotetext{
${ }^{1}$ Oscar Oszlak, La formación del Estado Argentino (Buenos Aires: Editorial de Belgrano, 1990), Tulio Halperín Donghi, Una Nación para el desierto argentino (Buenos Aires: CEAL, 1982) y Natalio Botana, "El federalismo liberal en Argentina: (1852-1930)", en Marcelo Carmagnani, Federalismos latinoamericanos: México, Brasil, Argentina (México: FCE, 1993).

${ }_{2}^{2}$ Esas áreas fueron denominadas jurídicamente territorios nacionales, a partir de la ley $\mathrm{N}^{\mathrm{o}} 28$, sancionada en 1862 durante la presidencia de B. Mitre.

${ }^{3}$ En términos generales, la campaña del coronel Rostagno, que en 1911 alcanzó a fijar una línea de fortines en el límite con el Paraguay, puso la discusión sobre los indígenas en un lugar secundario de la agenda política pero ello no significó el control absoluto sobre las comunidades. Oficialmente, la "guerra contra el indio" fue considerada concluida por el Gobierno Nacional el 31 de diciembre de 1917. En ese momento se abandonaron las políticas sistemáticas de reducción indígena y las campañas armadas contra grupos aborígenes. Sin embargo, siguieron existiendo enfrentamientos belicosos entre tropas militares y grupos indígenas hasta entrada la década del 20.
} 


\section{El Chaco y el Instituto Geográfico Argentino}

En términos generales, hasta la década de 1870 las políticas de expansión territorial del Estado argentino sobre los territorios indígenas habían sido puntuales y esporádicas, además de concentrarse en el avance sobre la Pampa.

El Chaco, hasta los 80's, era, ante todo, un territorio indígena, históricamente ocupado por comunidades lule, vilela, mataco-mataguayo, tobas, mocovíes y abipones, que no habían adoptado costumbres occidentales. Hasta 1870, se habían llevado a cabo numerosas exploraciones de reconocimiento del terreno con algunos intentos aislados y poco sistemáticos de ocupación efectiva a partir de sucesivas incursiones con resultados bastante efímeros, particularmente en lo vinculado a la determinación de caminos y fundación de pueblos ${ }^{4}$.

En 1872 comenzó a delinearse la organización política y administrativa del Chaco. Por decreto del presidente Mitre se creó el territorio nacional del Chaco. Se trataba de otorgar un estatus jurídico a tierras que, aunque quedaban enmarcadas dentro de los límites del territorio del Estado, no formaban parte de ninguna de las catorce provincias que lo componían ${ }^{5}$. Desde 1870 las expediciones al Chaco comenzaron a sucederse acompañando el proceso de su organización jurídico-administrativa ${ }^{6}$. Sin embargo, la falta de una programación sistemática de objetivos y operaciones militares, sumada a ciertos desacuerdos entre las autoridades del gobierno central y las autoridades locales en relación con las irregulares partidas presupuestarias, constituyeron los límites del avance militar efectivo sobre el territorio indígena.

La expedición militar que en 1884 encabezó el general B. Victorica, ministro de Guerra y Marina, clausuró un periodo de incursiones exploratorias, también llamado "etapa de fundación" "7 e inauguró una nueva modalidad de exploración signada por el intento sistemático de avanzar sobre el territorio indígena y de establecer colonias civilizadoras, fuertemente

\footnotetext{
${ }^{4}$ Una multiplicidad de factores determinaban la vulnerabilidad de esos trabajos: las condiciones climáticas, la inexistencia de una estructura administrativa in situ que mantuviera permanentemente la infraestructura y el alto costo que ello implicaba, entre otras. Entre las variables que explican los resultados poco exitosos de la empresa colonizadora cobraba una fuerza singular la lejanía con respecto a Buenos Aires desde donde se pretendía controlar y administrar estos territorios y el "peligro más o menos serio que siempre ocasionan vecinos tan turbulentos y de poca fe como son los indios". Arturo Seelstrang, Informe de la Comisión Exploradora (Buenos Aires: Eudeba, 1976), 87.

${ }^{5}$ Entre 1872 y 1900 se crearon diez territorios nacionales que cubrieron totalmente las áreas que no correspondían a jurisdicciones provinciales.

${ }^{6}$ Una reseña de las expediciones realizadas puede consultarse en Orlando Punzi, Historia de la conquista del Chaco (Buenos Aires: Vinciguerra, 1997). Un análisis del perfil exploratorio y asistemático de esas expediciones puede encontrarse en Carla Lois, El Gran Chaco argentino: de desierto ignoto a territorio representado. Un Estudio acerca de las formas de apropiación material y simbólica de los territorios chaqueños en los tiempos de consolidación del Estado-nación argentino. (Tesis de Licenciatura, Universidad de Buenos Aires, 1998), 53-79.

${ }^{7}$ Ernesto Maeder, Estudio preliminar (Buenos Aires: Solar Hachette, 1977), Jorge Fontana, El Gran Chaco (Buenos Aires: Imprenta de Ostwald y Martínez, 1881).
} 
militarizadas, conformadas por extranjeros e indígenas sometidos ${ }^{8}$. Esta modalidad de ocupación estuvo vinculada con la necesidad de incorporar mano de obra barata para los obrajes que, para esta época, constituían la principal actividad productiva. No obstante, no se escatimaba en recursos violentos para los indígenas considerados indomables: si bien la preocupación primera consistía en la apropiación territorial, ésta debía ser secundada por la "asimilación indígena".

Contemporáneamente y en estrecha relación con estos movimientos exploratorios numerosas instituciones desarrollaron trabajos científicos vinculados a la producción de conocimiento que en esa época se reconocía como geográfico ${ }^{10}$ : la necesidad de reconocimiento del territorio funcionó como un estímulo para el surgimiento de este tipo de instituciones porque proporcionaban informaciones en demanda. En este marco se inscribe la fundación del Instituto Geográfico Argentino en 1879, una propuesta de Estanislao Zeballos ${ }^{11}$ apoyada por un grupo de individuos de formación muy diversa, entre los que se incluían abogados, marinos, militares e

\footnotetext{
${ }^{8}$ En una carta del Gobernador de Corrientes a Simón de Iriondo (Ministro del Interior) del 13 de abril de 1875 puede leerse la relación entre reconocimiento territorial, ocupación militar y garantías a la población inmigrante y a su trabajo:

"Sería pues conveniente que, sin perjuicio de proceder inmediatamente al reconocimiento ordenado de los territorios sujetos a mi jurisdicción y a la delimitación de los cantones militares y pueblos a que se refiere la ley del año ppdo., se me autorice para comenzar a organizar un Piquete de Dragones, por lo pronto para garantir tantos intereses comprometidos seriamente, sin que esto obste a que en adelante [...] se le dé mayores proporciones y se formen otros cuerpos que garanten a los inmigrantes una labor tranquila y exenta de sobresaltos y la seguridad de que el fruto de sus trabajos no les será arrebatado por los indígenas.

Comprendo que el objetivo primordial del Gobierno al establecer autoridades en el Chaco no es garantir los capitales de Corrientes comprometidos sobre aquel suelo sino ofrecer garantías de seguridad a la inmigración europea que debe afluir sobre él.

La organización de esta fuerza, que será e núcleo de otra mayor, es tanto más necesaria cuanto que el establecimiento de los cantones militares debe preceder al envío de los inmigrantes a los pueblos que deben crearse a fin de que en ningún tiempo queden expuestos a las incursiones de los salvajes que, como he expuesto, desacreditarán a los ojos de la inmigración que miraría estos lugares como inhabitables por falta de seguridad cuando algún sin seso desgraciado viniese a azotar esos pueblos en su propia alma cuna". Servicio Histórico del Ejército, Buenos Aires (en adelante, SHE) Caja 6, Documento 1229.

${ }^{9}$ Así lo expresaba el general Victorica en una carta al coronel Carlos M. Blanco: "Es necesario perseguir los indios y gauchos matreros que encuentre en los desiertos y a los que no crea conveniente dar de alta en la Brigada debe remitirlos presos a Buenos Aires a disposición del Estado Mayor. A este respecto, cuanto se consigna tiene mucho mérito para la seguridad de esos territorios y la sujeción de las reducciones de los mismos indígenas que empiezan a llevarse a cabo". Benjamín Victorica, Campaña del Chaco (Buenos Aires: Publicación oficial, Imprenta Europea, 1885), 219. Los destacados son nuestros.

${ }^{10}$ Entre tales instituciones podemos mencionar: Instituto Histórico y Geográfico Argentino (fundado por Bartolomé Mitre en 1854), Oficina Topográfica Militar (dependiente de la Comandancia General de Armas de la República Argentina) y Sociedad Científica Argentina (1872).

${ }^{11}$ Estanislao Zeballos, abogado y doctor en jurisprudencia, se desempeñó como director y redactor de La Prensa, diputado provincial en la Legislatura de Buenos Aires (1879), diputado nacional por la Capital Federal (1880-1884) y diputado nacional por Santa Fe (1884-1888): llegó incluso a presidir la Cámara de Diputados en 1887. Fue ministro de Relaciones Exteriores de Juárez Celman, cargo que reasumió en 1891 durante la presidencia de Pellegrini. Fue profesor de Derecho Internacional Privado en la UBA, vicedecano de la Facultad de Filosofía y Letras de la UBA (1895) y Decano de la Facultad de Derecho de la UBA (1919). Luis Sanz, Zeballos. El tratado de 1881. Guerra del Pacifico (Buenos Aires: Pleamar, 1985).
} 
ingenieros ${ }^{12}$ y a la que adherían importantes personalidades de la ciencia y la política ${ }^{13}$. Puede sugerirse, entonces, que la Campaña de Roca (1879) parece tener alguna vinculación ${ }^{14}$ con la institucionalización de una sociedad interesada "particularmente en promover la exploración y descripción de los territorios, costas, islas y mares adyacentes de la República Argentina"15. No es frecuente encontrar en las páginas del Boletín del IGA alguna oposición o fuerte crítica a los proyectos políticos más significativos desde el punto de vista territorial (como, por ejemplo, los de las conquistas de los desiertos). Por el contrario, desde las prácticas y los discursos del Instituto Geográfico Argentino se colaboró en la construcción de imágenes territoriales fácilmente socializables y cientificamente demostrables que contribuyeron a internalizar al territorio como uno de los componentes de la ideología colectiva nacional. Además, gran parte de los debates que tuvieron lugar en estas instituciones se correspondían con las discusiones establecidas por los responsables de las decisiones políticas.

\section{Expediciones al Chaco: cruces entre los campos de la ciencia y la política}

En concordancia con los objetivos de la institución, expresados en el acta fundacional, entre la inmensa cantidad de trabajos geográficos publicados en el Boletín del IGA ocuparon un lugar privilegiado aquellos vinculados a las exploraciones de los "desiertos".

En la Argentina de fines del siglo XIX, el objetivo general y explícito de una institución científica de este tipo - a saber, la difusión de saberes geográficos ${ }^{16}$ - se articulaba con la

\footnotetext{
${ }^{12}$ Los asistentes a la convocatoria de Zeballos fueron: Martín Guerrico, Manuel José de Olascoaga, Clodomiro Urtubei, Rafael Lobos, Martín Rivadavia, el general Julio de Vedia, Francisco Host, Jordán Wisocki, Ramón Lista, el ingeniero Rosetti, Faustino Jorge, Mario Bigg, Pedro Pico, Clemente Fregeiro y Benjamín Aráoz. H. Goicoechea, El Instituto Geográfico Argentino. Historia e Indice de su Boletín (1879-1911, 1926-1928) (Resistencia: Instituto de Historia. Facultad de Humanidades. Universidad del Nordeste, 1970), 7. Cabe destacar el perfil militar de estos miembros y su compromiso con el proyecto territorial: de hecho, gran parte de ellos participaron de las expediciones a los "desiertos".

${ }^{13}$ Los socios honorarios fueron: el astrónomo norteamericano director del Observatorio Meteorológico de Córdoba Arthrop Gould, el naturalista director del Museo de Buenos Aires Dr. Germán Burmeister, el general Bartolomé Mitre, el publicista Manuel Ricardo Trelles y el Dr. Andrés Lamas -los tres últimos fundadores del Instituto histórico y geográfico del Río de la Plata-; más tarde se sumaron el Dr. Guillermo Rawson, Domingo Faustino Sarmiento, el general Julio A. Roca y, a su regreso de la campaña al Chaco en 1885, el general Benjamín Victorica, entre otros. H. Goicoechea, El Instituto Geográfico Argentino, 8.

${ }^{14}$ Esta vinculación puede constatarse relacionando: (a) año de fundación del Instituto Geográfico Argentino que coincide temporalmente con la campaña al Desierto; (b) la participación de Zeballos, fundador del IGA, en la campaña al Desierto; y (c) en el estrecho vínculo de algunos miembros del IGA con las actividades vinculadas a la Campaña al Desierto, como es el caso de los ingenieros militares Host y Wisocky que participaron en la confección de informes y cartografías.

${ }^{15}$ Instituto Geográfico Argentino (IGA), “Acta Fundacional”, Boletín del Instituto Geográfico Argentino (1879), $1: 79$.

${ }^{16}$ Las bases para la constitución del IGA y la posibilidad de incorporarse como miembro al Instituto reposaban en "haber aceptado por unanimidad el pensamiento de constituir en la República una sociedad especialmente consagrada
} 
preocupación y necesidad de conocer territorios sobre los que bien poco se sabía y de clasificar con criterios científicos y exactos aquellos datos que se fueran recolectando. De esta manera se pretendía colaborar activamente en la difusión de la situación de los territorios "desiertos", es decir,

[...] producir y socializar determinadas representaciones respecto del territorio [...] a través de la participación de [los] miembros [de las sociedades geográficas], de la elaboración y puesta en práctica de determinados proyectos territoriales, en el área estrictamente política" ${ }^{\prime \prime}$.

En esta clave pueden leerse la recurrente reproducción en el BIGA de documentos oficiales relativos a los "desiertos" (tales como resoluciones presidenciales, decretos, proyectos de leyes, leyes e, incluso, debates parlamentarios sobre las expediciones, la organización jurídica y el levantamiento de mapas en el Chaco). Por otra parte, como muchos miembros del IGA eran militares y participaron personalmente de las campañas al Chaco, muchos reportes, relatos de viaje y descripciones geográficas realizadas en las expediciones encontraron un lugar de difusión en las páginas del Boletín.

Los objetivos científicos del IGA tenían múltiples puntos de contacto con los objetivos políticos de la elite gobernante; uno de ellos era el conocimiento geográfico y la ocupación efectiva del territorio estatal. Fueron esas convergencias las que fortalecieron la relación entre el IGA y el Estado en dos direcciones: por un lado, las corporaciones geográficas proporcionaron un bagaje de información considerada científica y como tal, verdadera, que resultaba muy útil para legitimar y hacer incuestionables una serie de acciones orientadas a instaurar un proyecto político; por otra parte, el interés de los gobiernos por fomentar las actividades de las sociedades geográficas facilitaba las tareas encaradas por dichos institutos en tanto les proveía de fondos, personal y reconocimiento oficial.

En las empresas geográficas que hoy llaman la atención del mundo se asocian dos órdenes de intereses: los intereses de la civilización política, social y comercial de los pueblos, y los intereses mismos de la ciencia ${ }^{18}$.

La expedición puramente científica al mando del coronel Solá que el Gobierno Argentino ha enviado y la expedición terrestre preparada por Bolivia, tienden a objetos diferentes; la primera a la exploración y la segunda a la conquista, y por

\footnotetext{
al estudio y progreso de la ciencia geográfica", IGA, Boletín (1879), 1:131 y en "dar a conocer sus trabajos al país y al extranjero", IGA, Boletín (1879), 1:1.

${ }_{17}$ Perla Zusman, Sociedades Geográficas na promoção do saber ao respeito do território. Estratégias políticas e acadêmicas das instituições geográficas na Argentina (1879-1942) e no Brasil (1838-1945) (Tesis de Maestría, Universidad de San Pablo y Universidad de Buenos Aires, 1996).

${ }^{18}$ Conferencia del Dr. Estanislao Zeballos (presidente del IGA) con motivo de la recepción a la llegada de la campaña del Chaco de Thouar y Amadeo Baldrich el 17 de diciembre de 1883. IGA, Boletín, (1884), 5:1. Los destacados son nuestros.
} 
más buen resultado que ellas obtengan, la obra quedaría siempre incompleta por ambas partes.

Por un lado tendremos en el trayecto recorrido, un itinerario científico, hasta cierto punto ineficaz por los peligros que ofrece la frecuente amenaza de los salvajes, y por el otro, esto habría desaparecido, pero quedaría en pie lo principal, que es la posible navegabilidad del Pilcomayo ${ }^{19}$.

Es decir, en la idiosincrasia de estas instituciones, los aspectos científicos y los aspectos políticos debían conjugarse para obtener un diagnóstico y una práctica eficiente y eficaz. Cada una de estas dos dimensiones concebidas autónomamente no parecía suficiente para colmar las necesidades del momento: la exploración y la conquista eran vistas como dos caras de una misma moneda.

Llegados a este punto, cabe preguntarse entonces, ¿qué tipo de Geografía es aquella que se estaba produciendo a partir de estas sociedades geográficas? Se trata de un saber que se construye y participa de la constitución de nuevos espacios de dominación, donde la referencia a la geografía material es inmediata y donde no se alude a los cuadros teóricos de moda en la disciplina $u$ en otras áreas de conocimiento en Europa. Aun no existiendo un campo autónomo disciplinar, la geografía aparecería como un discurso científico, en directa relación con una geografía material donde hay una identificación entre el referente empírico y el discurso producido $^{20}$.

La geografía producida al interior del IGA, al igual que la que se construía al interior de otras instituciones geográficas como la Sociedad Geográfica Argentina, resultaba ser un saber "útil" a los fines del proyecto territorial estatal. Dicha utilidad era reconocida por el propio Estado, que fomentaba las actividades de estas instituciones. De esta manera, parece bastante transparente la existencia de una vinculación entre campañas militares de reconocimiento del territorio en la Argentina a fines del siglo pasado y la promoción de saberes legítimos sobre éste.

\section{El Atlas de la República Argentina publicado por el Instituto Geográfico Argentino}

Patrocinado por el gobierno nacional y bajo la dirección de Arturo von Seelstrang ${ }^{21}$, en 1886 el Instituto Geográfico Argentino publicó un atlas compuesto por 28 cartas $^{22}$. Esta obra, como era

\footnotetext{
${ }^{19}$ IGA, Boletín (1883) 4:87. Los destacados son nuestros.

${ }^{20}$ Zusman, Sociedades, 46.

${ }^{21}$ El ingeniero y topógrafo Arturo von Seelstrang, nacido en una familia noble de Prusia Oriental, llegó a Buenos Aires en 1863 contratado por el gobierno. Aquí participó en el trazado del ferrocarril a San Nicolás. Obtuvo el título de agrimensor en el Departamento Topográfico de Santa Fe (1866) y en Córdoba (1872). Para revalidar su título en Buenos Aires presentó un trabajo titulado Idea sobre la triangulación y mapa general de la República, donde desarrolló por primera vez un esquema de triangulación fundamental, algo inédito en la Argentina. En coautoría con A. Tourmente, publicó en Buenos Aires en 1875 el Mapa de la República Argentina, construido por orden del Comité Central Argentino para la Exposición de Filadelfia. Luis Brackebusch lo llevó a Córdoba donde fue
} 
habitual en publicaciones de este género, consta de una Introducción que antecede la sección cartográfica. La introducción del Atlas, firmada por el presidente de la Nación Julio A. Roca, consiste en la descripción de los antecedentes y de las fuentes utilizadas para la construcción de las cartas. A continuación de los antecedentes, se reproducen el proyecto de ley aprobado por el Senado y la Cámara de Diputados ${ }^{23}$ y el decreto firmado por el presidente haciendo efectiva la inversión de 25.000 pesos en virtud del cual el IGA quedaba

[...] encargado de la impresión y venta del Atlas, debiendo remitir al Ministerio de Instrucción Pública quinientos ejemplares de esta obra y destinando el producido de la venta a proseguir los estudios y trabajos que exija el perfeccionamiento sucesivo del Atlas y del Mapa General de la República que le ha servido de base.

La presencia del Estado en el proyecto cartográfico del IGA asumió un rol de considerable importancia, no sólo por el financiamiento que hizo posible su concretización, sino también por el aval y el reconocimiento que hacía del Atlas un decir "legítimo y autorizado". En este sentido, no resulta llamativo que la participación estatal sea destacada, incluso en el título mismo, el cual reza: Atlas de la República Argentina. Construido y publicado por el Instituto Geográfico Argentino. Bajo los auspicios del Exmo. Gobierno Nacional. Buenos Aires. 1892 (1886).

En la sesión de la Comisión Directiva del IGA del 2 de marzo de 1884, el director del Instituto se refirió al apoyo que el gobierno prometía al proyecto cartográfico:

Os doy la agradable noticia de que el Excmo. Señor Presidente de la República se ha servido visitar la Oficina Cartográfica de Córdoba donde estos trabajos se construyen y el local del Instituto en Buenos Aires, examinando con viva satisfacción las hojas de los atlas una a una, guiado por el criterio del que ha viajado todo su país observándolo detenidamente en servicio militar.

S.E. nos ha prometido la más decidida cooperación del Estado para una obra que reputa necesaria y urgente, y nos ha ofrecido decididamente concurrir con la suma

nombrado profesor de Topografía y, junto a él, publicó Ideas sobre la exploración científica de la parte noroeste de la República (IGA, Boletín, 1882, 3:312-315 y 323-331). Por encargo del IGA confeccionó el primer Atlas Científico de la República Argentina (1883-1893), compuesto de 29 hojas y 26 páginas de texto explicativo. En 1880 asumió como miembro activo de la Academia de Ciencias de Córdoba y en 1882 pasó a la categoría de miembro directivo. En los períodos 1883-1886 y 1894-1896 se desempeñó como decano de la Facultad de Ciencias Exactas, Físicas y Naturales. Cutolo, Nuevo diccionario biográfico argentino (Buenos Aires: Editorial Elche, 1968), 1:40. Además, actuó como Jefe Científico de la Comisión de Límites con el Brasil presidida por el General Garmendia. Finalmente, murió en 1896.

${ }^{22}$ Este atlas incluía diversos mapas, introducidos por una lámina de América del Sur representada según la proporción 1:15.000.000. A la carta general de la República Argentina (1:8.000.000) le siguen cartas generales y parciales de provincias argentinas (cuyas escalas oscilan entre 1:1.000.000 y 1:2.000.000) divididas en secciones "cuando la densidad de detalles lo requiriesen", las cartas de territorios federales y de las islas australes.

${ }^{23}$ El primer artículo de este proyecto expresa: "Autorízase al Poder Ejecutivo para invertir hasta la suman de veinticinco pesos moneda nacional en la impresión del Atlas Geográfico de la República trabajado por el Instituto Geográfico Argentino". 
de diez mil pesos moneda nacional para la impresión que está calculada en veinte mil nacionales ${ }^{24}$.

El compromiso del gobierno con esta obra no se expresaba solamente en cuestiones presupuestarias. En el marco de una fuerte política educativa estatal, con marcada intervención sobre las currículas, donde el perfil la Geografía como asignatura escolar asumías funciones "nacionalizadoras" 25 , en la sesión del 10 de enero de 1884 de la Comisión Especial del Mapa y Atlas de la República se decidió que "solicitará también, que se declare oficial el Atlas y se adopte para la instrucción en las escuelas públicas de la República"26.

\section{3. a. Los orígenes del Atlas del IGA}

Ante las numerosas críticas que funcionarios del gobierno y profesionales hacían de las cartografías circulantes ${ }^{27}$, quedó planteada la urgencia de enmendar tales deficiencias, e instalada la pertinencia del IGA para asumir esa tarea. La confección de un Atlas y un mapa de la República serían "la obra más trascendental acometida por el Instituto y la más necesaria y útil de las que una sociedad de esta naturaleza podía acometer"28. En esta empresa se concentraron gran parte de los miembros del IGA, se comprometieron elevadas partidas de fondos del Instituto e implicó que se estrecharan lazos con el gobierno, que manifestó de muy diversas formas -entre ellas el financiamiento de la primera edición- su interés por este emprendimiento.

\footnotetext{
${ }^{24}$ IGA, Boletin, (1884), 5:97.

${ }^{25}$ Silvina Quintero, "Geografía y nación. Estrategias educativas en la representación del territorio argentino (18621870)", Territorio $\mathrm{n}^{\circ} 7$ (1995), Buenos Aires: Instituto de Geografía, FFyL, UBA, 1995.

${ }^{26}$ IGA, Boletín (1883), 4:33.

${ }^{27}$ La obra de Martín de Moussy, el Atlas de la Confederación Argentina (1863) fue considerada como el documento cartográfico oficial hasta la elaboración del atlas del IGA. Consultar García Aparicio, La Carte de la République Argentine (Buenos Aires: IGM, 1913); Ricardo Orellana, "La cartografía básica de interés nacional. Su evolución”, Contribuciones científicas, Congreso Nacional de Geografía, XLVIII Semana de Geografía, (Córdoba: Sociedad Argentina de Estudios Geográficos, 1986); Instituto Geográfico Militar (IGM), 100 años en el quehacer cartográfico del país, 1879-1979 (Buenos Aires: IGM, 1979). Las críticas que hicieron blanco en él son una muestra del tipo de objeciones a las que se sometió a la cartografia circulante para fundamentar y justificar la necesidad de emprender una nueva obra cartográfica con el apoyo estatal. La opinión generalizada de los especialistas coincidía con la del Plenipotenciario argentino en Brasil, Luis Domínguez, quien aseguraba que "el Atlas de Moussy en que el Gobierno Nacional gastó tanto dinero, está plagado de errores, especialmente en los datos que consigna relativos a la Geografía Histórica, ramo tan interesante para el estudio y resolución de las cuestiones de límites con los Estados vecinos". IGA, Boletín (1880), 1:266. En el mismo sentido se expresó Zeballos, presidente del IGA: "Las cartas modernas desde las de De Moussy hasta la de Petterman, son igualmente imperfectas, porque las exploraciones eran todavía una vaga aspiración en las épocas en que ellas fueron grabadas". IGA, Boletín (1882), 3:161. Otros se dedicaron a puntualizar tales errores y también se ha señalado que Rudecindo Ibazeta, después de una expedición, le escribe al Inspector y Comandante General de Armas de la República Luis M. Campos que "M. de Moussy y obras muy competentes en sus mapas y datos geográficos del Chaco han cometido errores notables en diferentes sentidos. Moussy, por ejemplo, pone el pueblo de Rivadavia más arriba de Esquina Grande, siendo todo lo contrario; sufriendo la misma equivocación en la determinación de otras poblaciones". SHE, caja 8, Documento 1372.

${ }^{28}$ IGA, Boletin (1883), 4:98.
} 
Uno de los obstáculos a sortear a la hora de seleccionar las fuentes para iniciar la confección del Mapa era la inexistencia de "cartografía confiable". La Oficina Cartográfica del IGA instalada en la sede de Córdoba y a cargo de Arturo Seelstrang fue la encargada de organizar las tareas requeridas para reunir el material que serviría de fuente y referencia para el Atlas y para el Mapa de la República. Esta oficina, además, reclamó la participación de numerosos agentes y organismos, y dedicó una parte importante de los recursos humanos y financieros del IGA para cumplir con los objetivos fijados por el proyecto cartográfico:

Para organizar estos trabajos y llevarlos al término feliz que han alcanzado, el Instituto ha reunido cuanto material interesante ofrece la Geografía antigua y contemporánea de la República, relaciones de viajeros, croquis, planos, mapas oficiales y particulares, documentos públicos y datos privados que le han sido comunicados con espontaneidad de todas las provincias y territorios. Dibujantes y escribientes costeados por el Instituto han recorrido las oficinas públicas, copiando mapas, documentos, proyectos y trazados de caminos, ferrocarriles y telégrafos; los departamentos topográficos de la mayor parte de las provincias le han entregado sus mejores datos y donde esos departamentos no existen se ha nombrado comisiones especiales encargadas de recopilar y remitir los informes más fidedignos y prolijos ${ }^{29}$.

Para superar la dificultad de conseguir datos "confiables" la Oficina recurrió a informantes de gran prestigio social y político, como los gobernadores ${ }^{30}$, y reunió la mayor cantidad posible de fuentes, de las que se seleccionarían aquellas más virtuosas tras un análisis comparativo ${ }^{31}$.

\section{3. b. El Mapa de las "Gobernaciones de Chaco y Formosa" del Atlas de la República Argentina publicado por el Instituto Geográfico Argentino}

La lámina que se analiza en este punto corresponde a las gobernaciones del Chaco y Formosa. Está incluida en la sección cartográfica, donde cada mapa tiene inscripciones que se repiten en todas las láminas del Atlas que remiten, por un lado, a la pertenencia de cada lámina a la obra general y, por otro, a los responsables técnicos e institucionales ${ }^{32}$.

\footnotetext{
${ }^{29}$ IGA, Boletin (1884), 5:266.

30 "Con motivo de la construcción del mapa de la República, de que se ocupa el Instituto, y de la necesidad de que aquello sea lo más exacto posible, la Comisión Directiva había resuelto dirigirse a los Gobernadores de las provincias pidiéndoles la remisión de datos geográficos sobre los territorios de su jurisdicción" (firmado por Zeballos). IGA, Boletin (1883), 4: 46.

31 "Por tales medios el Instituto logró reunir en su oficina cartográfica, mil ciento cincuenta mapas, planos, croquis publicados o inéditos que han servido a la elaboración del Atlas después de un escrupuloso examen comparativo y depurativo en que han tomado parte personas y profesores de competencia reconocida, estando la revisión final del trabajo sometida a una Comisión de geógrafos y eruditos". IGA, Boletín (1884), 5:266.

${ }^{32}$ Por ejemplo, en la carta correspondiente a las gobernaciones del Chaco y Formosa, fuera del cuadro que delimita el texto propiamente cartográfico se consigna la siguiente información: por encima del margen superior, sobre el ángulo
} 
El título está inscripto en el ángulo superior derecho dentro de los límites de la carta, es decir, es constitutivo de la imagen. A continuación del título destacado en fuente de mayor tamaño ("Gobernaciones de Formosa y del Chaco"), se agregan las inscripciones correspondientes a la leyenda, la escala y la fecha de publicación. Es decir, existe cierta continuidad lineal entre el título y la leyenda: a la lectura del primero le sigue la inmediata lectura de la segunda.

izquierdo de la imagen, se inscribe el título de la obra completa -“Atlas de la República Argentina”-, y sobre el ángulo derecho, la ubicación del plano en cuestión en dicho Atlas -"Lám. XXI"-; de igual manera, debajo del margen inferior de la imagen se detalla, a la izquierda "Construido por A, Seelstrang" y, a la derecha, "Es propiedad del Instituto Geográfico Argentino", inscripciones a las que se agrega, en la parte central, la referencia a los responsable de la litografía y la impresión de la carta. 


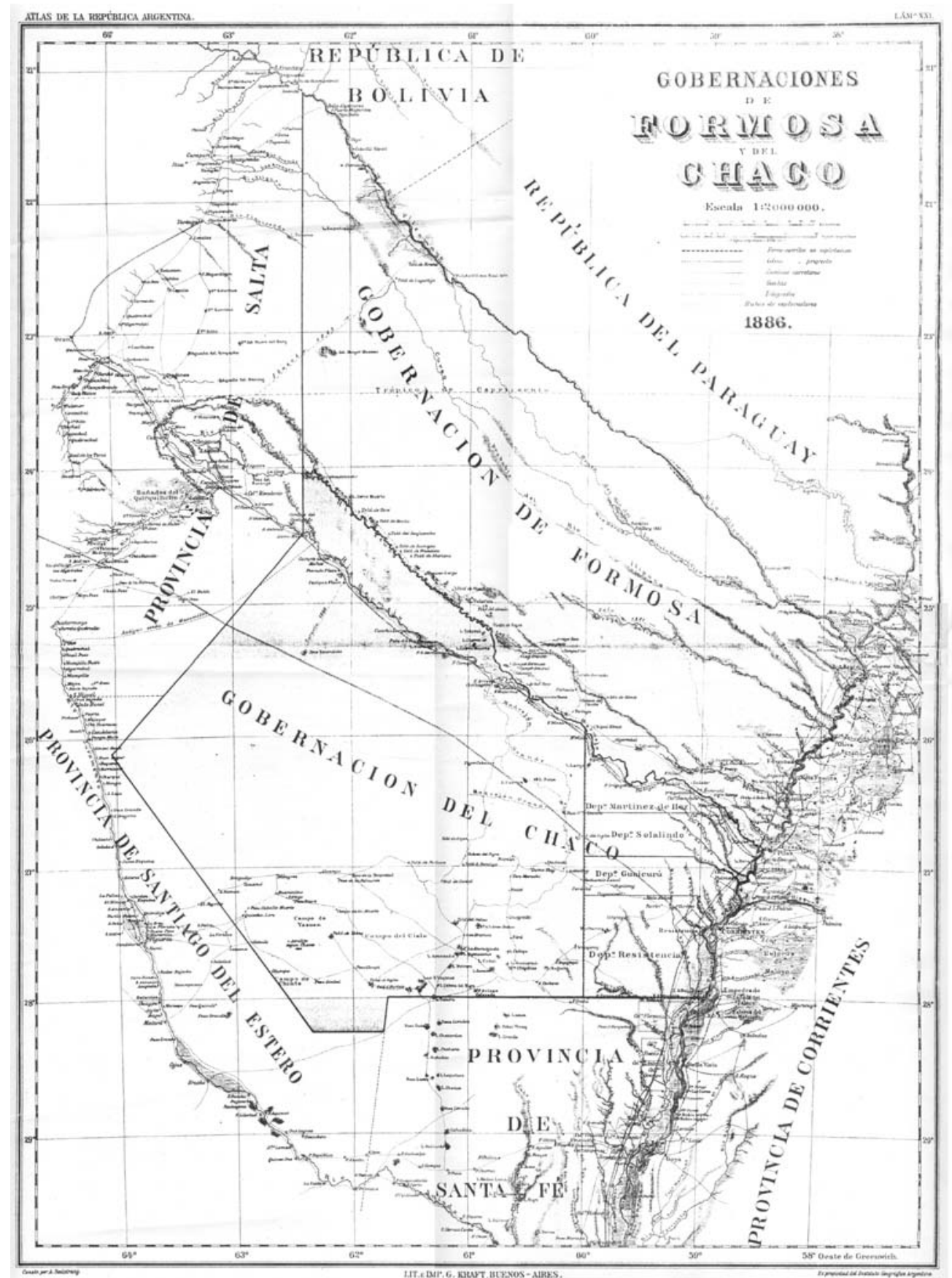

Mapa 1. Gobernaciones de Formosa y del Chaco. Atlas de la República Argentina (Buenos Aires: Instituto Geográfico Argentino, 1886), Lámina XXI. 
La leyenda de este mapa es idéntica a la de todas las láminas del atlas, lo que indica que en el atlas se unificaron y estandarizaron un conjunto de fenómenos considerados relevantes para la representación de todo el territorio argentino en su conjunto: "ferrocarriles en explotación", "ferrocarriles en proyecto", "caminos carreteros", "sendas" y "telégrafos". En rigor, se trata de elementos muy vinculados al progreso material impulsado por el gobierno, en el que el desarrollo de la infraestructura de comunicaciones ocupaba un lugar destacado por su importante rol en la articulación del interior del país con el puerto de Buenos Aires, devenido en el nodo central del modelo de circulación de mercancías del modelo agroexportador que significó la incorporación de la Argentina en el mercado mundial. El hecho de seleccionar estos aspectos para representarlos en los mapas y de estandarizar la leyenda para todas las cartas parciales de provincias y gobernaciones sugiere que se eligió no enunciar en la leyenda (uno de los lugares privilegiados de la enunciación explícita de los criterios del mapa) los fenómenos y procesos que explican la organización de este territorio. En síntesis, la leyenda de esta lámina deja de lado la especificidad del dominio indígena y las inestables formas de control territorial del Estado sobre el Chaco y Formosa, aspectos sobre los cuales apenas se ocupa y, por el contrario, apela a buscar en la imagen aquellas marcas de la organización estatal.

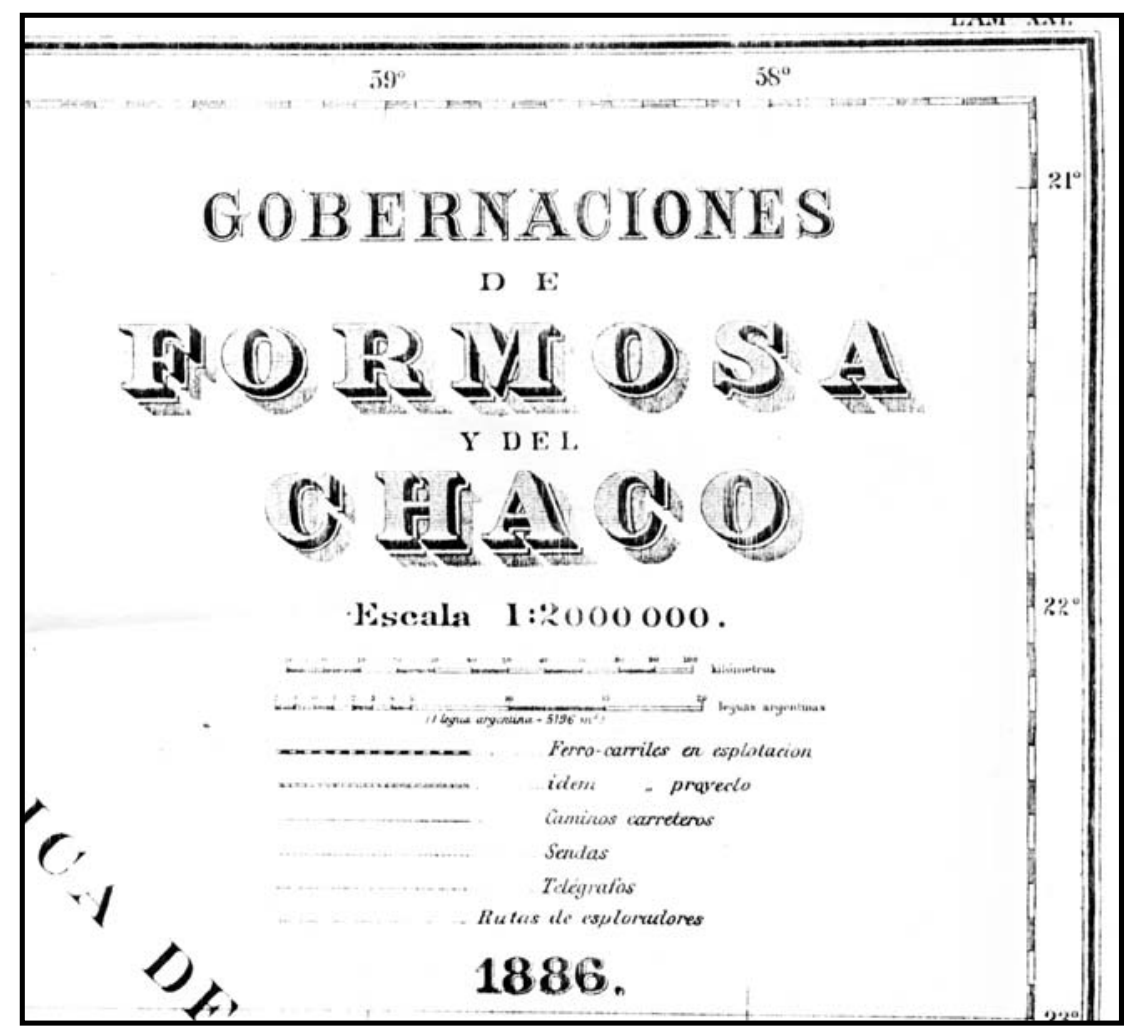

Mapa 2. Gobernaciones de Formosa y del Chaco. Atlas de la República Argentina (Buenos Aires: Instituto Geográfico Argentino, 1886), Lámina XXI 
La única distinción que propone la leyenda para el caso de las gobernaciones (también denominadas "territorios nacionales") consiste en el agregado del ícono "rutas de expediciones". Es decir, si bien se acepta que estos territorios tienen un estatus jurídico diferencial respecto del resto y que es necesario incorporar otros códigos para ajustar la mirada estándar sobre el territorio estatal impuesta por la leyenda, la marca distintiva de estos territorios se reduce a la cantidad de intentos militares por conocerlos, administrarlos y dominarlos. O sea, no se destaca ni el reconocimiento territorial de los indígenas ni sus asentamientos: sólo se explicita el avance militar.

Resulta llamativo que, si el mapa es apenas contiguo temporalmente a la expedición que desentrañaba la espesura del Impenetrable, se identifiquen redes de comunicaciones en territorios que hasta hacía poco tiempo estaban bajo completo dominio indígena. Sin embargo, en la parte más al sur del territorio de la gobernación del Chaco, una red de sendas pone en comunicación puntos acompañados de nombres propios. Se multiplican líneas (de sendas menores, de expediciones, etc.) que recrean la noción de red y, con ello, de comunicación, de territorios integrados y de control efectivo. Es cierto que no existe algún "ferrocarril en explotación" (es decir, en uso) en el Chaco de 1886, pero la voluntad de ligar de alguna manera ciertos sentidos -muy valorados social y económicamente en esa época- asociados al ferrocarril (progreso, modernidad, prosperidad) con los nuevos dominios ganados al indígena, se resuelve instalando en la imagen cartográfica un ícono lineal que atraviesa la gobernación del Chaco en su parte central correspondiente a "ferrocarril en proyecto".

Esta estrategia discursiva se articula con un mecanismo de lectura y que consiste en arrastrar la mirada rastreando el sentido de las líneas. De esta manera, en el vagabundeo visual sobre la imagen se asegura la observación (superficial, si se quiere) de ciertos rincones del texto cartográfico, cuyo recorrido está sugerido por la dirección de la línea desde zonas más densas, iconográficamente hablando, hacia zonas del mapa menos "intensas".

Esta forma de imaginar las gobernaciones de Formosa y del Chaco excluye e ignora la existencia de los grupos aborígenes. Y sostiene esa mirada antiindígena desde diversos ángulos: el título indica el status jurídico de esos territorios dentro de la organización estatal, la leyenda presenta la infraestructura de comunicaciones de las sociedades civilizadas, nombres españoles identifican todos los accidentes geográficos dibujados en el mapa y una incipiente división administrativa de la gobernación del Chaco desliza sutilmente que el proceso de ocupación definitiva de estas áreas ha comenzado. 


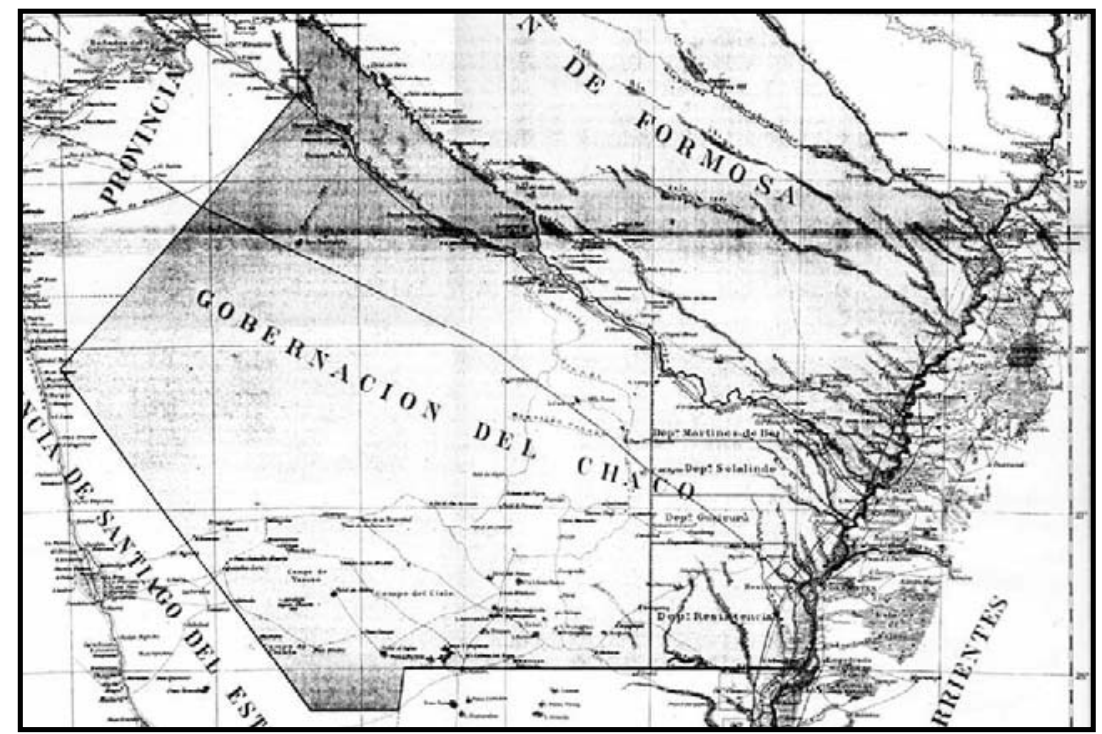

Mapa 3. Gobernaciones de Formosa y del Chaco (fragmento). Atlas de la República Argentina (Buenos Aires: Instituto Geográfico Argentino, 1886), Lámina XXI

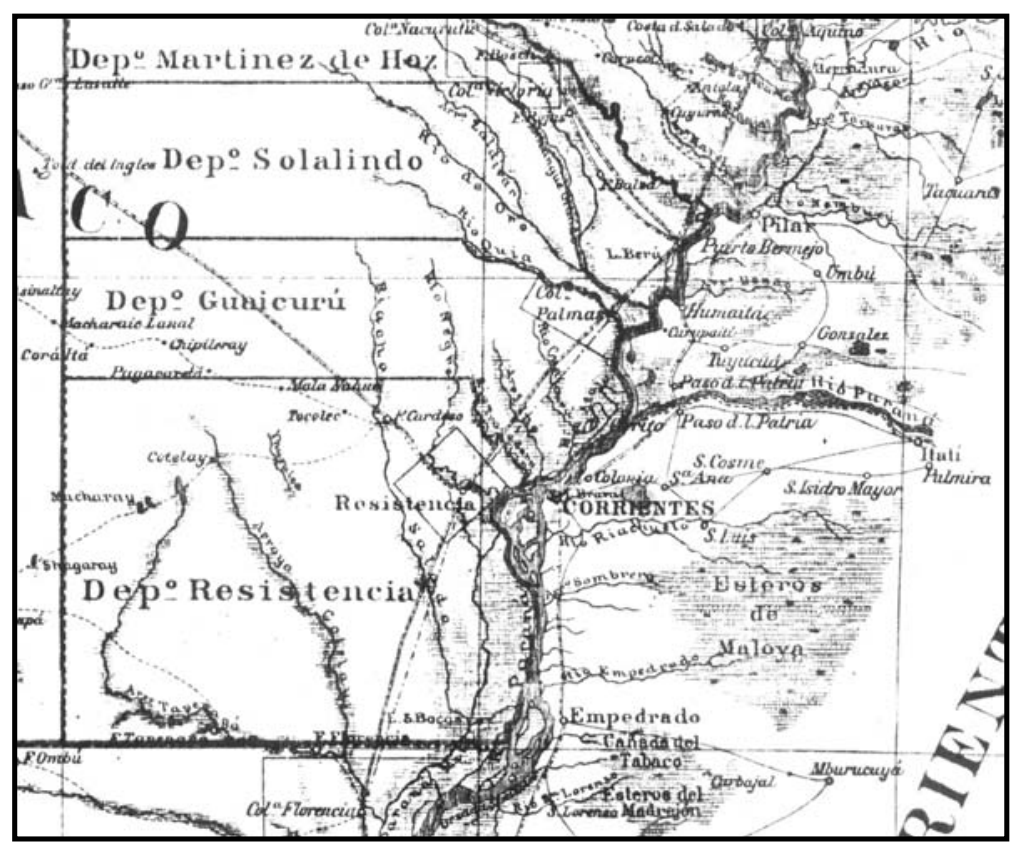

Mapa 4. Gobernaciones de Formosa y del Chaco (fragmento). Atlas de la República Argentina (Buenos Aires: Instituto Geográfico Argentino, 1886), Lámina XXI 


\section{Imágenes del Chaco: un desierto fértil}

A lo largo de las páginas del Boletín del IGA encontramos que recurrentemente se pensó el Chaco en términos de desierto, estableciendo una relación de sinonimia (nunca fundamentada) entre "Chaco" y "desierto".

El anclaje de la imagen de "desierto" para hacer referencia al Chaco funcionaba recuperando ciertas dimensiones del significado literal y original, entre las que se ponderaba el rasgo de vacío. Aunque podría sugerirse que no se trataba de un área vacía, ya que estaba repleta de vegetación impenetrable y de indígenas "hostiles", lo cierto es que desde los cánones del positivismo decimonónico la ausencia de civilización era el vacío. Y un vacío que debía ser llenado.

Pero sobretodo al hablar de desierto, se ponía el énfasis en el referente geográfico y nada se decía sobre los habitantes del lugar. Ignorando la existencia de las comunidades aborígenes que lo ocupaban, fue como se construyó el vacío y, consecuentemente, el desierto. Así, la apropiación -y la legitimación de la apropiación- parecía imponerse sobre el vacío, sobre la nada, lo que ponía fuera de discusión la cuestión indígena y posicionaba al desierto como escenario óptimo para la civilización.

La metáfora de desierto se utilizó también para fundamentar la necesidad del relevar topográficamente el Chaco y cartografiarlo. En una publicación del Instituto Geográfico Militar se afirmó respecto de la expresión desierto aplicada al Chaco:

El término 'Desierto' engloba más un sentido de desconocimiento geográfico que una acción natural pues en estas tierras inmejorables se encontraban riquezas potenciales para ganaderos y agricultores ${ }^{33}$.

El desierto equiparado al desconocimiento geográfico parecía no dejar lugar a dudas acerca de la necesidad impostergable de conocerlo. Una de las modalidades de conocerlo era cartografiándolo. Claro que para cartografiarlo había que penetrar en el Impenetrable.

La metáfora del desierto movilizaba también la idea de barbarie y otras connotaciones políticas: en el contexto del imperialismo europeo y el auge del positivismo, los desiertos debían ser colonizados, apropiados, civilizados y cartografiados. Es decir, pensar el desierto implicaba necesariamente la urgencia de vaciarlo y transformarlo, mediante la apropiación nominal y simbólica, en un no-desierto.

Pero vaciar el desierto no era solamente una empresa militar. Había que pensar el desierto: era necesario construir y socializar una imagen que articulara estos sentidos. Entre los ámbitos en que la imagen de desierto circuló, las sociedades geográficas tuvieron un desempeño destacado,

\footnotetext{
${ }^{33}$ IGM, 100 años, 21.
} 
en tanto sus prácticas tenían la particularidad de producir discursos legítimos sobre el territorio ${ }^{34}$.

\section{Pensando un nuevo Chaco: las miradas renovadas no ven el desierto}

Hacia fines del siglo XIX y en las primeras décadas del siglo XX, cuando la ocupación militar mostraba los esperados resultados, el interés científico por la "cuestión chaqueña" perdió gran parte del lugar que ameritaba unos años antes en el Boletín del IGA: el casi exclusivo interés por la frontera interior y la lucha contra el indígena fue reemplazado por la preocupación por las fronteras exteriores ${ }^{35}$. Del mismo modo, cuando, tras la expedición de Victorica, se consideró haber desequilibrado las fuerzas en la lucha contra los indios en favor del proyecto estatal, también cambió el discurso sobre los indígenas, devenidos en "naturales de la Nación", según una expresión que el propio Victorica utilizó al regreso de la campaña ${ }^{36}$. Los indígenas, entonces, pasaron a ser una "especie adaptada al medio", útil para una mejor explotación de las riquezas, y cuya situación inferior en la escala humana estaba más vinculada a las vicisitudes de la evolución natural que al destino intrínseco de los indígenas, tal como puede apreciarse en el discurso del Comandante Fontana, en la Recepción de Victorica en los salones del IGA el 2 de marzo de 1885:

Haber sometido a tanta tribu es uno de los timbres de honor que pueden ostentar en todo tiempo los que han dirigido la expedición al Chaco, tan sabia y tan prudentemente. [Existen] ventajas étnicas del momento ya que en su esencia, la radicación de una raza vigorosa en un suelo casi desierto es cuestión de tiempo, de adaptación climatérica y de la selección que se opera en el desenvolvimiento regular de las fuerzas y en la marcha compleja no pocas veces fugitiva de los acontecimientos humanos. El indio en su expresión actual es como un producto de aquel suelo, típicamente caracterizado por el aislamiento en que se ha desarrollado. Puesto en contacto con razas superiores se tornará en un factor económico y será de gran utilidad en el progreso de las industrias que empiezan a implantarse en el $\mathrm{Chaco}^{37}$.

Al regreso exitoso de Victorica no sólo cambió el discurso sobre los indígenas sino que también mutaron el discurso y las imágenes sobre el área geográfica en cuestión: el Chaco dejaba ya de ser nombrado recurrentemente como "desierto" y comenzaba a ser pensado como parte del

\footnotetext{
${ }^{34}$ Zusman, Sociedades, 46.

${ }^{35}$ Remitimos a la comparación de los índices de diversos tomos: en el tomo 2 (1881) no hay ningún artículo referido a los límites internacionales, en tanto que en el tomo 13 (1892) hay cuatro artículos centrados en discusiones sobre este tema y otros tantos que narran exploraciones y situación de colonias en territorios en conflicto.

${ }^{36}$ IGA, Boletin (1885), 6:105.

${ }^{37}$ IGA, Boletín (1884), 5:266. Los destacados son nuestros.
} 
"territorio estatal argentino". Fue únicamente en ese momento cuando apareció en el Boletín una reflexión explícita sobre los usos de la metáfora del desierto chaqueño:

A lo desconocido se le exagera y se le reviste casi siempre de cualidades terribles. La palabra desierto en todos los pueblos y en todos los tiempos se presenta envuelta en una penumbra de prestigio mágico y medroso. La imaginación popular asocia a ella un mundo de visiones fantásticas y poco simpáticas y tranquilizadoras, y era natural también que el Chaco pagase su parte de tributo a esta lejana y tradicional manera de considerar lo desconocido.

Así, ese territorio, [...] ha sido sucesivamente clasificado de malo, unas veces, y otras pintados con las exageradas claridades de un Paraíso, tachado inhabitable por lo ardiente de su clima, otras se ha creído ver allí la esplendidez de la naturaleza pintada en los primeros versos de Flor de un día. Error todo: ni tan malo, ni tan absolutamente bueno ${ }^{38}$.

\section{A modo de conclusiones}

A partir del análisis de una variedad de artículos, conferencias y prácticas y vinculaciones institucionales del IGA en relación con las campañas militares al Chaco es posible delinear la postura institucional del IGA con respecto a las políticas estatales orientadas a imponer el dominio efectivo sobre el territorio: el interés "geográfico" por la región chaqueña se ajustó a los pulsos de alza y baja del interés político por esa área y los discursos científicos producidos en esas coyunturas estuvieron funcionalmente orientados a sostener argumentaciones de carácter político.

En los textos publicados por el IGA el Chaco había sido bautizado como desierto. Los usos y los significados de esta metáfora variaban y combinaban una retórica cientificista con una retórica poética, impregnándola así de la legitimidad de las ciencias decimonónicas al mismo tiempo que se recuperaba, emotivamente, la idea de un espacio vacío.

Hablar de desierto era hablar de espacio. En cambio, hablar del Chaco era hablar de indígenas, porque el Chaco siempre había sido dominado por los indígenas. Sin embargo, en las cartografías el Chaco nunca fue representado como un vacío. Por el contrario, aún cuando la inexistencia de información habría justificado que se dejaran áreas del mapa en blanco, el Chaco aparecía "lleno" de íconos de vegetación que dan una impresión visual de espacio lleno, conocido y ocupado. Estas estrategias retóricas articuladas en los textos cartográficos se fundamentan, por un lado, en la necesidad de representar y exponer la integridad territorial del Estado en textos científicos que podían funcionar como documentos y, por otro, en la de "ocupar" territorios nominal e intelectualmente: las prácticas cartográficas también son

\footnotetext{
${ }^{38}$ IGA, Boletin (1884), 5:148.
} 
prácticas de nominación, y desde ellas no sólo se impone un juego de relaciones de poder y un orden del mundo social, sino que también se consolida una imagen -fácilmente socializableque el resto de la sociedad debe tener de ese territorio.

Las representaciones simbólicas acompañaron el proceso político de expansión territorial "gestando un sentido común respecto del espacio [...], una mentalidad acerca de sus temas, un horizonte espacial, colectivo" ${ }^{39}$. Pensar el desierto, entonces, precedió y acompañó la transformación del Chaco en un no-desierto.

Desierto y cartografia fueron dos formas "científicas" significativas de pensar el Chaco en los tiempos de consolidación del Estado argentino $\mathrm{y}$, ambas, se articularon en las prácticas científicas y militares de quienes llevaron a cabo su apropiación nominal y material, pero además vehiculizaron una multiplicidad de significaciones que se anclaron en el sentido común de la época y generaron ciertos mecanismos de aceptación y legitimación social de prácticas políticas.

\footnotetext{
${ }^{39}$ Antonio Moraes, Ideologias geograficas (San Pablo: Hucitec, 1988), 32. En portugués en el original. Los destacados son del original.
} 


\section{Bibliografía}

Aparicio, García. La Carte de la République Argentine. Buenos Aires: IGM, 1913.

Botana, Natalio. "El federalismo liberal en Argentina: (1852-1930)". En Federalismos latinoamericanos: México, Brasil, Argentina, Marcelo Carmagnani, ed. México: FCE, 1993.

Cutolo. Nuevo diccionario biográfico argentino. Buenos Aires: Editorial Elche, 1968.

Fontana, Jorge. El Gran Chaco. Buenos Aires: Imprenta de Ostwald y Martínez, 1881.

Goicoechea, H. El Instituto Geográfico Argentino. Historia e Índice de su Boletín (1879-1911, 1926-1928). Resistencia: Instituto de Historia. Facultad de Humanidades. Universidad del Nordeste, 1970.

Halperín Donghi, Tulio. Una Nación para el desierto argentino. Buenos Aires: CEAL, 1982.

Instituto Geográfico Argentino (IGA), Boletín del Instituto Geográfico Argentino 1 (18791880)-13 (1892).

Instituto Geográfico Militar (IGM). 100 años en el quehacer cartográfico del país, 1879-1979. Buenos Aires: IGM, 1979.

Lois, Carla. El Gran Chaco argentino: de desierto ignoto a territorio representado. Un Estudio acerca de las formas de apropiación material y simbólica de los territorios chaqueños en los tiempos de consolidación del Estado-nación argentino. Tesis de Licenciatura. Buenos Aires: Universidad de Buenos Aires, 1998.

Moraes, Antonio. Ideologias geograficas. San Pablo: Hucitec, 1988.

Orellana, Ricardo. "La cartografía básica de interés nacional. Su evolución". En Contribuciones científicas, Congreso Nacional de Geografía, XLVIII Semana de Geografía. Córdoba: Sociedad Argentina de Estudios Geográficos, 1986.

Oszlak, Oscar. La formación del Estado Argentino. Buenos Aires: Editorial de Belgrano, 1990.

Punzi, Orlando. Historia de la conquista del Chaco. Buenos Aires: Vinciguerra, 1997.

Maeder, Ernesto. Estudio preliminar. Buenos Aires: Solar Hachette, 1977.

Quintero, Silvina. "Geografía y nación. Estrategias educativas en la representación del territorio argentino (1862-1870)", Territorio (Buenos Aires) 7 (1995).

Sanz, Luis. Zeballos. El tratado de 1881. Guerra del Pacífico. Buenos Aires: Pleamar, 1985.

Seelstrang, Arturo. Informe de la Comisión Exploradora. Buenos Aires: Eudeba, 1976.

Victorica, Benjamín. Campaña del Chaco. Buenos Aires: Publicación oficial, Imprenta Europea, 1885.

Zusman, Perla. Sociedades Geográficas na promoção do saber ao respeito do território. Estratégias políticas e acadêmicas das instituições geográficas na Argentina (18791942) e no Brasil (1838-1945). Tesis de Maestría. Universidad de San Pablo y Universidad de Buenos Aires, 1996. 